Identity without Supervenience

Author(s): John Gibbons

Source: Philosophical Studies: An International Journal for Philosophy in the Analytic

Tradition, Vol. 70, No. 1 (Apr., 1993), pp. 59-79

Published by: Springer

Stable URL: https://www.jstor.org/stable/4320396

Accessed: 02-11-2018 18:49 UTC

JSTOR is a not-for-profit service that helps scholars, researchers, and students discover, use, and build upon a wide range of content in a trusted digital archive. We use information technology and tools to increase productivity and facilitate new forms of scholarship. For more information about JSTOR, please contact support@jstor.org.

Your use of the JSTOR archive indicates your acceptance of the Terms \& Conditions of Use, available at https://about.jstor.org/terms 


\section{IDENTITY WITHOUT SUPERVENIENCE}

(Received 1 April, 1992)

In this paper, I am primarily interested in the connection between relational, or externalist, descriptions of content-bearing mental events on the one hand, and the question of whether or not the events referred to by these descriptions are in any sense external to the individual to whom they are ascribed. I will argue that when we talk about a paradigmatic type of mental event, occurrent thoughts, we use descriptions involving relational properties of the event ("content properties") but the event referred to is purely internal to the individual. If content properties are relational but nonessential features of mental events, we have the possibility of token physicalism without the supervenience of content properties on internal physical properties. Thoughts are neurological events, but content properties do not supervene on neurological properties. And though our ordinary identification of thoughts is in terms of their content, what makes a thought the event that it is may not be a matter of its having that content. Making sense of this view is the project of this paper.

I am interested in defending a version of nonreductive materialism. Since Davidson, ${ }^{1}$ one of the most common ways of formulating nonreductive materialism is in terms of events. Every mental event is a physical event, but mental properties are not physical properties and are not reducible to physical properties. Since it is so common, I will adopt this formulation. But this is not to say that there cannot be other formulations of nonreductive materialism, even with an ontology that does not admit events. To adopt this formulation of nonreductive materialism, however, is not to adopt any particular conception of events. We will return to this question below. Also following Davidson, I will assume that a mental event is an event that has a true description containing a mental predicate. ${ }^{2}$ I also assume that we can spot mental vocabulary when we see it. For example, any event description con- 
taining a verb of propositional attitude refers to a mental event if it refers at all. Finally, I will assume that it makes sense to speak of the essential and accidental properties of events. The event of my writing this paper could have been the very same event even if it had taken place in a room whose walls were painted a slightly darker color. It could not, however, have been an event which consisted of someone else playing tennis. I will not here be arguing for any essentialist claim, but I do need to assume that the distinction makes sense.

In "Individualism and the Mental,"3 Tyler Burge is primarily concerned with showing that social factors are relevant to the determination of the contents of our thoughts. He presents a by now familiar thought experiment in which we imagine holding constant the internal physical properties of an individual while the contents of the person's thoughts differ because of differences in the way other people use the language. In addition to presenting and defending this argument for the relevance of social factors for the determination of content, Burge also draws various consequences from this view. In particular, he presents an argument against any version of physicalism which attempts to identify content-bearing mental events with physical events in an individual. Here is a reconstruction of that argument: ${ }^{4}$

(1) Let " $b$ " rigidly designate the physical (neural) event correlated with Oscar's thought that he has arthritis in the thigh.

(2) In the counterfactual situation, b occurs but Oscar does not have any thought with the content that he has arthritis in the thigh.

(3) If a thought has a certain content in a possible world, then it has that same content in every world in which it exists or occurs.

(4) If b were Oscar's thought that he has arthritis in the thigh, then it would occur in the counterfactual situation without having the content that he has arthritis in the thigh, contradicting (3). 
(5) Therefore, b is not Oscar's thought that he has arthritis in the thigh.

There are, essentially, two ways around this argument: focus on (2), or focus on (3). Premise (1) is a stipulation, and (4) simply explains how the first three premises entail the conclusion. It is logically superfluous. The obvious way to deny (2) is to reject Burge's main conclusion and argue that he has made some mistake in attributing contents to Oscar, either in the actual or counterfactual situation. If Oscar does not actually think that he has arthritis in the thigh, then we cannot say that b occurs in the counterfactual situation. If there is no such thought, then our stipulation in (1) fails to secure a referent for "b." And if Burge is mistaken in describing the counterfactual situation, then we can say that in that situation, Oscar does have a thought with the relevant content.

One obvious way to deny (3) goes like this. First we suppose that there are two kinds of content: "narrow content" and "wide content." The idea is supposed to be that while the wide contents of Oscar's thought differ in the actual and counterfactual situations, the narrow content remains the same. So we reject (3) when the content under discussion is wide content but accept a reformulation that is restricted to narrow content. Since the contents that differ are wide, the argument needs to make reference to this sort of content in (3) to make trouble for an identity theory.

Neither of these will be my strategy. I take it that Burge has sufficiently blocked the first strategy in the main part of his paper. And the second strategy leaves us with the obligation to provide an account of "narrow content," but I am sceptical that such an account can be given. More importantly, however, neither strategy gets to the heart of the problem. The conflict between content essentialism, the view that thoughts have the same content in every world in which they occur, and a token identity theory is much more direct than Burge's argument suggests. To see the conflict, consider the following argument.

(6) This particular neural sequence could have had a different content.

(7) Oscar's thought at t that he has arthritis in the thigh is this particular neural sequence. 
(8) Therefore, Oscar's thought at t that he has arthritis in the thigh could have had a different content.

First a word about the logical form of (6) and (8). "This particular neural sequence" and "Oscar's thought at that he has arthritis in the thigh" are in purely referential position. In each sentence, the predicate denies that the relevant event has its content essentially. Now a token identity theory will entail that some sentence like (7) is true and that neural sequences have contents. So given an identity theory, (6) is perfectly obvious regardless of what "kind" of content is at issue. As a matter of fact, the neural event stands in all sorts of interesting and important relations to inputs, outputs, other states of the brain, and the rest of the world. On just about any account of content, it has the content that it does in virtue of standing in these relations. But if these relations are contingent, if the event could have occurred without standing in those relations, then the neural event could have had a different content or no content at all.

Of course, in the above argument, we simply assume an identity theory. We could just as easily have assumed content essentialism and argued against an identity theory. The point of the argument is simply to show that the conflict between the two views does not depend on a particular conception of content. Unlike Burge's argument, this argument rests on a very minimal claim about the determination of content. All we need to assume about content is that if thoughts are neural events, then the content of the thought is determined by contingent relations between the event and something else. We need not take any stand on the relevance of relations to things outside the individual to whom the thought is ascribed. A rejection of wide content is not sufficient. We must reject either content essentialism or an identity theory.

We have, however, some independent grounds for accepting a token identity theory. ${ }^{5}$ We ordinarily assume that our thoughts, our beliefs and desires, cause much of our behavior. So suppose a mental event $m$, a belief and desire pair, causes me to move my arm in a certain way, e.g., to reach for a glass of water. Assuming the closure of the physical, there will be some physical event $p$ which causes this physical event of my moving my arm. Now either $m$ and $p$ are each independently 
sufficient causes for my moving my arm, in which case we have overdetermination, or $m$ and $p$ are both necessary and only jointly sufficient, in which case we violate the closure of the physical, or $m$ is identical to $p$. Using this sort of argument by elimination, we arrive at a token identity theory.

My strategy to motivate the denial of (3) is to look at the role content essentialism plays in our thinking about the mental. First of all, as we have seen, it conflicts fairly directly with an identity theory which we have some reason to accept. But I will argue that we have no reason to accept content essentialism and that the view itself really does no work. I will begin with some considerations about individuation. We will see that our ordinary ideas and practices concerning the individuation of thoughts do not entail essentialism. This means first of all, these ideas and practices provide no grounds for content essentialism, and secondly, that we can reject the essentialism without altering or replacing the ideas or practices. Next we will look at a familiar view of events which may be taken to suggest, but does not entail, content essentialism. This view is faulty for reasons having nothing to do with the mental and should be revised. The revised view of events lends no support whatsoever to content essentialism. If anything, it makes it more suspicious. Finally, I will look at certain intuitions which have motivated the idea of narrow content. These intuitions should be taken as reasons to reject content essentialism rather than reasons to believe in narrow content.

We are introduced to content essentialism through a criterion of identity, or principle of individuation, for thoughts. The standard, or most common way, of referring to a token thought is to refer to the person to whom it occurs and the time and content of the event. Furthermore, it is an implicit part of our ordinary practice of thought attribution that thought $\mathrm{x}$ and thought $\mathrm{y}$ are the same (token) thought just in case $x$ and $y$ occur to the same person at the same time and have the same content. As Burge says,

If person, time, and content are the same, we would normally count the thought event the same. If any one of these parameters differs in descriptions of thought events ..., then the events or occurrences described are different. ${ }^{6}$ 
Let's assume that this is correct. The problem is that Burge moves from a criterion of identity to an essentialist premise:

Now one might codify and generalize this point by holding that no occurrence of a thought . . . could have a different . . . content and be the very same token event. ${ }^{7}$

Clearly, we can't get essentialism from a criterion of identity. Suppose that we individuate objects in the following way: $\mathrm{x}$ and $\mathrm{y}$ are the same physical object just in case they are in the same place at the same time. We do not infer from this that physical objects have their places essentially. And the Identity of Indiscernibles does not entail that objects have all their properties essentially. ${ }^{8}$

It could be that Burge intends his remarks as a cross-world criterion of identity for thoughts, which would have the form "If $\mathrm{x}$ and $\mathrm{y}$ are thoughts, then $\mathrm{x}$ in world 1 is $\mathrm{y}$ in world 2 iff $\mathrm{x}$ and $\mathrm{y}$ occur to the same person at the same time and have the same content." This criterion would entail content essentialism, but it is not clear that it is implicit in our ordinary practices of thought attribution. This criterion is actually stronger than content essentialism, since it also entails subject and temporal essentialism. But consider a detective recounting the thought processes that lead to the apprehension of a criminal. "It suddenly occurred to me that something was out of place on the piano. If that had happened just a few seconds later, it would have been too late to stop the culprit." The most straightforward semantic analysis of the second sentence takes "that" to refer to the mental event reported in the first sentence. The point of the second sentence, on this analysis, is to say what would have happened if that event had occurred a few seconds later. If it is possible for this sentence to be nonvacuously true on this analysis, then it must be possible for a mental event to occur slightly later than it actually does. So if this is the correct analysis of the second sentence, the cross-world criterion is false.

Of course, a more complicated analysis can be provided. "That" may be a disguised description or a "pronoun of laziness," and the recovered description can be given narrow scope with respect to the modal operator. On this analysis, we have the detective saying what would have happened if an event of the same sort had occurred slightly later. Ordinary language by itself gives us no reason to complicate our semantic analysis in this way. If there are reasons for the complication, 
they must be metaphysical reasons concerning what is and what is not essential to events. But if the cross-world criterion requires an argument, and any argument for the criterion would be, in part, an argument for content essentialism, it does not help to start with the criterion and hope to get essentialism from that.

A principle of individuation, or criterion of identity, does not entail essentialism, and a cross-world criterion is itself in need of support. There is, however, another sense in which we individuate thoughts in terms of their contents. We ordinarily type individuate or classify thoughts in the following way: If $\mathrm{x}$ and $\mathrm{y}$ are thoughts, they are of the same kind if they have the same content. Of course we can type individuate a group of objects in any number of ways. But for a number of purposes, including explanations and generalizations in both folk and scientific psychology, as well as conveying and relaying information, type individuation in terms of content is dominant. So, in addition to what attitude a person takes toward a content (believing, desiring, and so on), the content properties of a thought are among the most important to us for type individuation.

Type individuation of thoughts in terms of content lends no more support to content essentialism than token individuation, i.e., a criterion of identity. Consider an analogy. We know that two things are the same kind of artifact if they have the same functions(s) or purpose(s). We know this just by thinking about what an artifact is, just as we know that thoughts are of the same kind if they have the same content by thinking about what a thought is. But first of all, we do not infer from this fact about artifacts that they have their functions essentially. This thing, which happens to be a table, could have been produced for a very different purpose, perhaps as a purely decorative art object. Of course, it is a necessary truth that if something is a table, it has this particular function or purpose. But it is the conditional as a whole that is necessary. If we are interested in the essential properties of individuals, we are concerned with de re necessity. In fact, we need the necessitation of the consequent, and this is not forthcoming from the necessity of the conditional unless we suppose that being a table is an essential property.

Secondly, being a table is a relational property. ${ }^{9}$ It does not locally supervene on the physical properties of tables because whether or not you have this property is partly determined by the intentions of your 
creator which may in turn involve a wider social context. It follows that table talk, and artifact talk generally, cannot be reduced to talk about the intrinsic physical properties of objects, just as thought talk cannot be reduced to talk about the intrinsic physical properties of brains. But this failure of reduction does not by itself keep us from identifying this table with the chunk of matter of which it is composed. Barring certain unrelated problems about identity through time, we can say that every token table is identical with some chunk of matter even though the property of being a table is not reducible to and does not even supervene on the intrinsic properties of that chunk of matter.

In the case of artifacts, the situation is quite clear. Our most ordinary descriptions and type individuation of artifacts involves a nonessential, relational property of them. But even though relations to things outside of a room go into making a thing a table, we have no trouble identifying the table with something inside the room. This, at least, is one clear case of identity without local supervenience. In the case of thoughts, then, it makes sense to suppose that Oscar's thought (at t) that he has arthritis in the thigh is a neurological event in his brain even though the property of being a thought that one has arthritis in the thigh does not supervene on the (internal) neurological properties of the brain. Again, our ordinary descriptions and type individuation of thoughts involves their content properties. But though things outside of the brain go into making a thought have a certain content, we may be able to identify the thought with something inside the brain.

The claim that we individuate thoughts in terms of their contents can be taken in a number of ways. If we spell this out in terms of a criterion of identity, it is true but lends no support to content essentialism. If we spell it out in terms of a cross-world criterion of identity, it is at least as controversial, if not more controversial than content essentialism. So if we are looking for reasons to believe content essentialism, this understanding of the claim will not help. And if we spell out the claim about individuation in terms of a principle of classification, or in terms of type individuation, this also lends no support to essentialism. Without an alternative reading of the claim, it is safe to assume at this point that considerations concerning individuation are irrelevant to content essentialism. Let's turn to some general considerations about events and how we identify them. 
III

The standard way of referring to a token thought is to refer to the person to whom it occurs and the time and content of the event. This can be taken as evidence for various principles of individuation. But the principles do not help the essentialist cause. But perhaps our ordinary means of identifying thoughts can lend more direct support to content essentialism. Suppose we adopt the following two theses about events and their names.

(E) Events are property exemplifications.

This is usually taken to involve, among other things, the following criterion of identity for events. The event of an object $x$ having property $P$ at time $t$ is the same event as $y$ having $P^{\prime}$ at $t^{\prime}$ just in case $x=y, t=t^{\prime}$, and $\mathrm{P}=\mathrm{P}^{\prime}{ }^{10}$ The property exemplified by the object at the time is called the constitutive property of the event, and the object which exemplifies this property is the subject of the event.

(N) Our ordinary descriptions of events typically contain predicates which express the constitutive properties of the events to which they refer.

For example, "the party we had at Timothy's last night" will refer to an event whose constitutive property is having a party. The group of people there will be the subject.

Since we typically refer to thoughts using descriptions which involve the content of the thought (e.g. "Oscar's thought that he has arthritis in the thigh"), the conjunction of (E) and (N) entails that when we talk about thoughts, we typically refer to events that have content properties as constituents. Of course, this view no more entails content essentialism than any criterion of identity entails the corresponding essentialist claim. But the following sort of reasoning is seductive. If the event is nothing over and above the individual having the property at the time, then how could the same event in another possible world be the exemplification of a different property?

I think the move from "nothing over and above" to essentialism can be resisted in general. But in this case, I think we should resist the idea that content properties are constituents of events. This is entailed by the 
conjunction of $(\mathrm{E})$ and $(\mathrm{N})$, but we have independent reasons to reject this conjunction. In particular, we should reject $(\mathrm{N})$. Without the conjunction, we have no reason to think that contents are constituents of thoughts, and the replacement view of events makes sense of the denial of content essentialism.

Attractive as it is, the conjunction of $(E)$ and $(N)$ has some serious defects. For example, it entails that there are a great many more events occurring at any particular place and time than we would normally think. ${ }^{11}$ Any definite description which expresses a property distinct from having a party will, on this view, refer to an event distinct from the party we had at Timothy's, even if the subject and time are the same. We may try to refer to that party using such descriptions as "the dance party Timmy threw" or even "Lisa's birthday party." Since this latter description, for example, expresses the property of having a birthday party, and since this property is distinct from the property of having a party, the two descriptions refer to events with distinct constitutive properties, i.e., to distinct events.

We know that Lisa's birthday party was the only party we had at Timothy's last night. But the conjunction of $(E)$ and $(N)$ entails that there were a number of events occurring at Timothy's last night, all of which happened to be parties. There was the birthday party, the dance party, and the good time had by all. It should be possible for people to use these different descriptions to refer to the same event. So either $(E)$, or $(N)$, or both must go. Now we can reject $(N)$ without rejecting $(E)$, but we cannot reject $(\mathrm{E})$ without rejecting $(\mathrm{N})$. We cannot hold that definite descriptions of events refer in virtue of expressing constitutive properties unless we know what a constitutive property is. But our only account of constitutive properties is contained in $(\mathrm{E})$. So $(\mathrm{N})$ must go either way, either alone or along with $(\mathrm{E})$.

Rejecting (E) along with $(\mathrm{N})$ involves producing a replacement. But (E)'s main competitor, the view of events as regions of space-time, has difficulties of its own. ${ }^{12}$ On the other hand, $(N)$ is independently suspicious. According to (N), our definite descriptions of events function in a radically different manner from our definite descriptions of objects, properties, and points in time. "The table in this room" refers to an individual that has a certain property, the property of being the only table in the room. If we have a unified treatment of definite 
descriptions, "the party we had at Timothy's last night" should refer to an individual that has a certain property, the property of being the only party we had at Timothy's last night. The individual that has this property is an event, and the same event can have the property of being Lisa's birthday party. According to $(\mathrm{N})$, on the other hand, the former description refers in virtue of expressing the property of having a party, and this property is had by a group of people.

The rejection of $(N)$ is sufficient to avoid the multiplication of events. "The dance party that Timmy threw was Lisa's birthday party" is true because the two descriptions are coreferential. Finding a replacement for $(\mathrm{N})$ is simple: treat descriptions of events in the same way you treat other descriptions. That is, we should replace (N) with (D).

(D) An event description of the form "the F" refers to the only (contextually relevant) event which is $\mathrm{F}$.

Here the distinction between a Fregean and Russellian account of descriptions is irrelevant. In both cases, descriptions refer in virtue of properties exemplified by the referent. If the referent is an event, we should be concerned with properties of the event, like being fun, and lasting all night, rather than the constitutive properties of the event which are properties exemplified by the subject of the event.

So events are property exemplifications, but not every event name contains a predicate which expresses the constitutive property of the event to which it refers. We can think of constitutive properties as highly complex and specific. As Bennett says, $P$ is the constitutive property of an event $\mathrm{e}$ when "the whole intrinsic truth about $\mathrm{e}$ is that it is an instance of P."13 For "instance," you can read "exemplification." An instance of a property is not the individual that exemplifies it but the exemplification by the individual. This has also been called a "trope."

"The party we had at Timothy's last night" refers to an event whose constitutive property is not the property of having a party, but rather a far more complex property which will determine, given the relevant contextual information, who said what to whom and when. A far more interesting and descriptive name could refer to the same event even if it contained predicates which expressed properties that are not even coextensive with the property of having a party. In fact, if constitutive 
properties are this complex and specific, we will very rarely, if ever, use names which express their constitutive properties. But this should not be too surprising. Our names and descriptions of individuals or properties rarely, if ever, reveal the whole intrinsic truth about them. "The property of being round" does not tell us what it is to be round; "the color of my true love's hair" tells us little or nothing about the intrinsic nature of that color; and "the table in this room" says nothing about the constituents of the table. There is no reason to believe that descriptions of events are any different.

If constitutive properties of events are this complex and specific, we cannot, in general, read them off of our ordinary descriptions of events. ${ }^{14}$ But this does not mean that we cannot discover those constitutive properties. If all you know about the table in this room is that it is a table and that it is in this room, you know next to nothing about its constituents. It could be made of wood, or steel, or glass. To know about the constituents, you need more than an ordinary description; you need to investigate. If all you know about the party last night at Timothy's is that it was a party at Timothy's, you know nothing about its constituents. But if you were there, you would have a much better idea of its constituents.

A party, of course, is a complex affair, and consists of a number of things going on at once. One of the many things that went on was Jack and Diane flirting in the corner. They could have flirted in any number of ways. But what the flirting actually consisted of was, among other things, her saying just that in just that way. Her saying it that way, in turn, consisted of her making certain sounds. The sounds could have meant something different in a different language, just as her tone of voice could have suggested something different in a different cultural environment. But there should not be any difficulty in separating the event, her making certain sounds, from the contextual factors that give the event a certain significance.

Also, the constitutive property of an event is in general logically independent of the property expressed by the predicates in our ordinary descriptions of events. Consider the constitutive property of Timothy's party. This highly specific property is surely not necessary for being a party. A different party could have had different people saying different things. But if constitutive properties exhaust and are 
exhausted by the intrinsic nature of their events, then the constitutive properties of many events will not entail the property involved in our ordinary event descriptions. To suppose otherwise, as Bennett does, ${ }^{15}$ is to suppose that our ordinary event descriptions refer only in virtue of the intrinsic properties of events. But this is clearly not the case. There need not be an intrinsic difference between opening night and dress rehearsal. An event is an opening night largely in virtue of its temporal relations to other events. Something is a christening of a ship rather than performance art or simple vandalism because it takes place in a certain social context. Think of all the social, cultural, and historical relations necessary to make something a wedding. ${ }^{16}$

Regardless of the importance of their relational properties, we have no trouble locating these events in space and time. The wedding started around noon and took place in a church on Elmwood Avenue. At least in many cases, we have no trouble distinguishing the event from the customs, traditions, and historical events which are necessary for the event to have a certain property, i.e., being a wedding. We do not think that the event is spread out in space and time so that we include in the event all of the relations necessary to make it a wedding. Otherwise, it would not start at noon or take place in a church. Even though things outside of a church go into making something a wedding, we have no trouble locating and identifying the wedding with something inside the church.

So, events are property exemplifications. The constitutive properties of events determine the intrinsic nature of the event. But descriptions of events function the same way other descriptions function. The predicates in the descriptions express properties had by the event (e.g., being $a$ wedding) rather than constitutive properties which are had by the constitutive objects (e.g., getting married). Often, the properties expressed by the descriptions are relational, and even nonessential, properties of the event (e.g., being the first party of the summer). But if descriptions of events refer in exactly the same way that other descriptions refer, there is no problem referring to events using relational, nonessential properties. "The table in this room" refers to an individual partly in virtue of that individual standing in a certain contingent relation to a room.

Applying this view to thoughts is quite straightforward. According to 
(E) and (D), we can say that "Oscar's thought that $\mathrm{p}$ at t" refers to a property exemplification, but the property exemplified by Oscar is highly complex and specific. If Oscar's thought has some purely intrinsic phenomenological properties, these can be included in the constitutive property of the event even though these properties are neither necessary nor sufficient for a thought to have that content. If the thought has some biological basis, this too can be included in the constitutive property regardless of its independence of the content property. What is important to the constitutive property is that it determine the intrinsic nature of the event. And while this intrinsic nature may be discovered through philosophical reflection or through empirical research, it will not be discovered by reflecting on our ordinary descriptions of the events.

So, "Oscar's thought that $\mathrm{p}$ at $\mathrm{t}$ " refers to an event in virtue of that event's having a certain content and occurring to Oscar at a certain time. These are properties of the event. They need not have anything to do with the constitutive properties of the event. In fact, if event descriptions function like other descriptions, it makes sense to suppose that at least some of the properties in virtue of which the description refers are relational, or even, nonessential. So the rejection of content essentialism fits quite nicely with an independently motivated account of events and event descriptions. And the rejection does not require any serious modification in our thinking about the mental. It does not, for example, require an alternative principle of individuation for thoughts, or an alternative way of referring to thoughts.

Finally, a further difficulty with the conjunction of $(\mathrm{E})$ and $(N)$ is that it rules out the possibility of nonreductive materialism. According to (N), "Oscar's thought that $\mathrm{p}$ at $\mathrm{t}$ " will refer to an event whose constitutive property is thinking that $p$. According to $(\mathrm{E})$, no event is identical to this event unless it is an exemplification of the same property. In particular, we cannot say that this thought is the event of some brain having some neurological property unless that neurological property is the property of thinking that $p$. In other words, there is no token identity without type identity. But it is reasonable to prefer a general theory of events which leaves nonreductive materialism open as an interesting philosophical possibility. Of course, the conjunction of (E) and (D) does not entail nonreductive materialism, but it does leave 
the possibility open. I take it that this is a further reason to prefer (D) to $(\mathrm{N})$.

So far, my argument against content essentialism has been in terms of economics: its acceptance is costly; its rejection is cheap. The price of content essentialism is the rejection of an identity theory. Burge's argument ((1) to (5)) from content essentialism against an identity theory and my argument $((6)$ to (8)) from an identity theory against content essentialism show the conflict between the two views. We cannot have both. I have tried to show that giving up content essentialism does not involve giving up much else. And the proposed view of events is intended to make sense of the rejection. Given the importance of relational, nonessential properties in our talk about weddings and parties, not to mention tables and chairs, the importance of content properties in our talk about mental events should not lead us to essentialism.

But in addition to this sort of reason, we have some intuitive motivation for rejecting content essentialism. Suppose you look at a table and say, "That table is brown." According to the best semantics we have for indexicals, ${ }^{17}$ you express a singular proposition: the proposition has the table itself as a constituent. Now if you believe what you say, if what is said is what is believed, then the content of your thought is the same singular proposition. Given the well known difficulties with description theories, this is the most plausible characterization of the content of your thought. So for these theoretical reasons, we conclude that the actual object of reference is a constituent of the content of the thought.

The narrow content intuitions, however, do have some initial plausibility. According to this view, the very same thought could have occurred even if that table never existed. I think we should accept this claim but refuse to draw the moral which is usually drawn. The narrow content theorist, assuming content essentialism, concludes that there must be some other conception of content which does not involve external objects as constituents. But as far as I know, no plausible substitute has been proposed which deserves to be called content. Now if the same thought could have occurred without the table, but could 
not have had the same content without the table, then the thought does not have its content essentially. By rejecting content essentialism, we can grant the intuitive motivation for the narrow content project without thereby accepting the project itself.

Similar remarks hold for the predicative components of thoughts. According to the narrow content intuitions, my recent thought that water is wet could have occurred even if no samples of water ever existed. The wide content theorist can accept this claim of ontological independence. Such a theorist is only committed to the necessity of the following conditional: If a thought has, in a certain world, the content that water is wet, then there must be some samples of water in that world. Without content essentialism, there is nothing wrong with saying that the thought that water is wet occurs in a world without water but does not have, in that world, the content that water is wet. "The thought that water is wet" refers, in the actual world, to an event in virtue of its having a certain content in this world. If we reject content essentialism, we can refer to the event in this way and talk about the same event in a world in which it has a different content. There is nothing more mysterious about this than asking about what would have happened to the table in this room if it had been outside.

If we accept the independence claim, the claim that my thought that water is wet could have occurred even if no samples of water ever existed, without accepting narrow content, we must reject content essentialism. According to the independence claim, the same thought could occur in a world without water. According to the wide content theorist, the thought could not have, in that world, the content that water is wet. If the same thought could occur without having that content, then the thought does not have the same content in every world in which it exists. So content properties are nonessential. So the narrow content intuitions, as I understand them, together with a truth conditional conception of content entail the rejection of content essentialism.

The narrow content intuitions can be used in an argument against content essentialism. To anyone who is moved by the intuitions but has theoretical difficulties with the idea of narrow content, this is a good reason to reject content essentialism. And these reasons have nothing to do with physicalism. But even those who deny having the relevant 
intuitions, or who deny their relevance or importance, cannot deny the widespread existence of these intuitions in others. Such a theorist, it seems, requires some sort of explanation for why so many people have these intuitions. The theorist can say that all of these people are just wrong in their intuitions. But a more plausible explanation is that the intuition is correct, but that the narrow content theorist has drawn the wrong moral from these intuitions. The denial of content essentialism gives us such an explanation of these intuitions.

It seems that the identity theorist would want to say something like this. Each mental event is a physical event. It has mental properties, and it has physical properties. Now if it makes sense to talk about some particular event and to ask for its essential properties, we might want to say that the event's essential properties are a subset of its physical properties. Maybe we believe in the primacy of the physical in some strong sense. Not only is every event a physical event, but the physical properties of an event make it the event that it is. This is compatible with the claim that some of these events will also have mental properties contingently, and even that these properties are not reducible to physical properties. We can have physicalist essentialism without reduction or an alternative principle of individuation. It is just that with thoughts, as with tables and weddings, the most natural way to refer to and type individuate them is in terms of relational, nonessential properties, in the case of thoughts, their content properties. Perhaps such an essentialist view could not be used in an argument for the identity theory. But it is a consistent position. To deny the possibility of such a position, as Burge does when he assumes content essentialism, neglects one plausible alternative open to the identity theorist.

The view I am presenting, then, says that each token mental event is a physical, neural event in an individual and that the content properties of these events are nonessential properties of the events. The very same thought could have had a different content. This view seems to be open to the following objection. Consider Oscar's thought that he has arthritis in the thigh. This thought is false. Now consider the very same thought in Burge's counterfactual situation in which Oscar has the very 
same diseases. On my view, the very same thought is true. What accounts for this difference in truth value if the relevant facts about Oscar's thigh remain the same?

The answer is not very hard to find. Consider the sentence "George Bush is the President of the US in 1992." This sentence is a physical object, a syntactic string. It has its meaning, or content properties, nonessentially. It could have meant something other than what it does. As things stand, the sentence is true. But there are two different kinds of situation in which it is false. First, George Bush might not have been President. But even if we keep all the facts about Bush and the Presidency fixed, a situation in which the sentence is false is one in which it means that snow is green. This is exactly what happens to Oscar's thought. It changes its truth value not because of a change in the things that it is about but because it is about different things.

Burge discusses a similar analogy in a footnote. ${ }^{18}$ But he discusses the view that contents are sentences which is certainly not my view. The relevant difficulty. he has with an analogy between thoughts and sentences is that sentences can be identified independently of their contents while it is not obvious that thoughts can. It is not clear what relevance identification has to essentialism. If it is spelled out in terms of individuation or in terms of our ordinary descriptions, I hope to have shown that identification has nothing to do with essentialism.

Finally, suppose that Burge is right that relations between the individual and the environment are relevant to the determination of content. On the one hand, we might say that the event that is Oscar's thought is in some sense spread out onto the world both spatially and temporally. ${ }^{19}$ This way, all of the relevant relations between Oscar and the environment are already part of the event and we do not have to posit any essential relational properties of the event. On the other hand, we might just say that Oscar's thought is an internal neural event which is type individuated by nonessential relational properties. I think that when you come right down to it, the second option is far more plausible.

For most of this paper, I have been trying to motivate the rejection of content essentialism. First of all, content essentialism is incompatible with a token identity theory with or without wide content, and we have independent reasons for accepting such an identity theory. Secondly, 
the rejection of content essentialism provides us with an explanation for the narrow content intuitions without committing us to a rejection of a truth conditional conception of content. Finally, according to an independently motivated view of events and event descriptions, it makes perfect sense to suppose that contents are not constitutive of thoughts. If contents are not constitutive of thoughts, there is much less temptation to think of them as essential and probably more temptation to think of them as relational and nonessential. Although I grant that there is a certain intuitive plausibility to the idea that thoughts have their contents essentially, I think that upon reflection, we should reject that idea. It could be that much of the idea's plausibility derives from certain considerations concerning individuation or identification. But as we have seen, these considerations really lend no support to content essentialism.

If we do reject content essentialism, we can understand how thoughts can be individuated in terms of a property which involves relations to things outside of a person while the thoughts themselves are completely internal to the person. We can have externalist descriptions of internal events because the properties used in the description are nonessential. And this leaves open the possibility of identity without supervenience. A thought is a neurological event in a person, but the content properties of that thought do not supervene on the intrinsic neurological properties of that event. ${ }^{20}$

\section{NOTES}

1 See "Mental Events," in Essays on Actions and Events (Oxford: Oxford University Press, 1980), p. 209.

2 Davidson, p. 211.

3 Tyler Burge, "Individualism and the Mental," Midwest Studies in Philosophy vol. 4, French et al. eds. (Minneapolis: University of Minnesota Press, 1979).

${ }^{4}$ Burge, pp. $110-111$.

5 This argument is taken from Jaegwon Kim's "Dretske on How Reasons Explain Behavior" in Dretske and His Critics, Brian McLaughlin ed. (Oxford: Basil Blackwell, 1990).

6 Burge, p. 111. We should add attitude type (belief, desire, etc.) to this list.

7 Burge, p. 111.

8 This lack of entailment has been pointed out before. See James Van Cleve, "Why a Set Contains its Members Essentially," Nous, 19 (1985): 585-602, and Lawrence Lombard, Events: A Metaphysical Study (London: Routledge and Kegan Paul, 1986), pp. 187-189. The logic of the situation is fairly straightforward. A criterion of identity 
has the following form: If $\mathrm{x}$ and $\mathrm{y}$ are things of kind $\mathrm{K}$, then $\mathrm{x}$ is $\mathrm{y}$ iff $\mathrm{x}$ and $\mathrm{y}$ share certain relevant properties. The conjunction of Leibniz' laws is the most general such criterion. But if we pick the right kind $\mathrm{K}$, we can often find a proper subset of properties which is both necessary and sufficient for identity. So for thoughts, the relevant properties are content properties, attitude type properties (being a belief, desire, etc.), subject properties (occurring to Frank Sinatra etc.), and temporal properties. Letting "P" range over just these properties and letting "Tx" mean that $\mathrm{x}$ is a thought, we have (TH):

$$
\square(\mathrm{x})(\mathrm{y})[(\mathrm{Tx} \& \mathrm{Ty}) \rightarrow(\mathrm{x}=\mathrm{y} \leftrightarrow(\mathrm{P})(\mathrm{Px} \leftrightarrow \mathrm{Py}))]
$$

Now we are trying to get from this to content essentialism. So we need something like " $\square \mathrm{Ca}$ " where $\mathrm{C}$ is some particular content property. So now we instantiate and assume that $\mathrm{a}$ and $\mathrm{b}$ are thoughts. But with a necessary conditional and its antecedent we only get the consequent, not the necessitation of the consequent. So let's assume that $a$ and $b$ are essentially thoughts. Of course, a hard line materialist would want to deny this. But for the sake of the argument, and for the moment, let's assume it. This gives us the necessitation of the antecedent, and from this and $(\mathrm{TH})$ we get

$$
\square(\mathrm{a}=\mathrm{b} \leftrightarrow(\mathrm{P})(\mathrm{Pa} \leftrightarrow \mathrm{Pb}))
$$

Now we assume that $a$ is $b$. And since "a" and " $b$ " are rigid, this is a necessary truth. This gives us the necessitation of the right side of the biconditional. By instantiating for "P" we get

$$
\text { (CE?) } \square(\mathrm{Ca} \leftrightarrow \mathrm{Cb})
$$

This is about as close as (TH) will get us to content essentialism, but it is not very close. We have already assumed that $a$ is $b$ and that " $a$ " and " $b$ " are rigid. So (CE?) basically says that a has a certain property iff it has that property. And this is true, but it clearly does not entail that it has that property essentially or even that it has it at all. Of course, we can assume "Ca" but this will only give us "Cb." What we want is " $\mathrm{C} \mathrm{Cb}$." And the only way we can get from (CE?) to that is to assume " $\square \mathrm{Ca}$." In effect, to get from (CE?) to content essentialism you need to assume content essentialism.

9 Let's say that a property $P$ is a relational property of an individual $x$ iff the proposition that $\mathrm{x}$ is $\mathrm{P}$ entails that there exists an individual $\mathrm{y}$ which is wholly distinct from $\mathrm{x}$. An individual $y$ is wholly distinct from $\mathrm{x}$ iff $\mathrm{y}$ is not $\mathrm{x}$, and $\mathrm{y}$ is not a proper part of $\mathrm{x}$, and $y$ does not share a proper part in common with $x$. I will use both "intrinsic" and "internal" to describe properties that are not relational.

10 Jaegwon Kim, "Events as Property Exemplifications," in Action Theory, Brand and Walton eds. (Dordrecht: D. Reidel, 1976), p. 161.

11 Jonathan Bennett discusses this objection in Events and Their Names (Indianapolis: Hackett, 1988), pp. 78-82.

12 Again, see Bennett, pp. 119-122.

13 Bennett, p. 93.

14 Similar remarks go for the relation between event descriptions and the subjects of the events described. "The dance party at Timmy's" does not tell you who was there.

15 Bennett, p. 128.

16 If you like stories about intrinsically indistinguishable doubles, consider this. In the actual world, a wedding takes place, the minister having been ordained, and so legally licensed to marry people, though the mail. In the counterfactual situation, the mail order ordination company is a fraud, and so the minister is not actually ordained. So in the actual world, a legal wedding takes place, but the intrinsically indistinguishable event in the counterfactual situation is not legally a wedding. Since the minister in the counterfactual situation does not know she is not ordained, there is no difference in the actions, beliefs, or intentions of anyone involved. Perhaps more complicated stories can 
be told in which in the counterfactual situation, an intrinsically indistinguishable event, or perhaps the very same event, takes place in a culture with different customs and practices, and so the event is not a wedding.

17 David Kaplan, "Demonstratives" in Themes From Kaplan, Almog et al. eds. (Oxford: Oxford University Press, 1989), pp. 481-563.

18 Burge, p. 121, note 15.

19 Colin McGinn seems to believe that thoughts, and the mind itself, are spread out in this way. See, for example, Mental Content (Oxford: Basil Blackwell, 1989).

${ }^{20}$ I would like to thank Tyler Burge, Jaegwon Kim, Ernie Sosa, and an anonymous reader from Philosophical Studies for helpful comments on earlier versions of this paper.

Department of Philosophy

Brown University

Providence, RI 02912

USA 